\title{
Expression of the co-signaling molecules CD40-CD40L and their growth inhibitory effect on pancreatic cancer in vitro
}

\author{
SONGBING HE $^{1 *}$, HUA ZHAO $^{1 *}$, MIN FEI $^{2}$, YUGANG WU $^{1}$, LIANG WANG $^{1}$, XINGGUO ZHU $^{1}$ and DECHUN LI \\ ${ }^{1}$ Department of General Surgery and ${ }^{2}$ Jiangsu Institute of Hematology, \\ The First Affiliated Hospital of Soochow University, Suzhou 215006, P.R. China
}

Received February 22, 2012; Accepted April 2, 2012

DOI: 10.3892/or.2012.1790

\begin{abstract}
We investigated the expression of the co-signalling molecule CD40 in pancreatic cancer and the growth inhibitory effect of the recombinant soluble human CD40 ligand (rshCD40L) in pancreatic cancer cell lines. Twenty-six cases of pancreatic cancer tissues and corresponding paratumoral normal tissues were immunohistochemically analyzed for CD40 expression. The association of CD40 expression with clinicopathological parameters, including clinical stage, pathological grade, invasion and metastasis, were statistically analyzed. The serum SCD40 levels in pancreatic cancer patients were examined by ELISA. The expression of CD40 in the pancreatic cancer cell lines Panc-1, Aspc-1 and Miapaca-2 was examined by RT-PCR and flow cytometry. The growth inhibitory activity of rshCD40L on pancreatic cancer cell lines was determined by MTT assay. Tumor cell apoptosis was detected by TUNEL and Annexin V/ PI double staining method. CD40 was positive both on the membrane and in the cytoplasm of tumor cells, $69.2 \%(18 / 26)$ of the cases were positive for CD40. CD40 expression was significantly higher in pancreatic cancer tissues compared to adjacent normal tissues $(\mathrm{P}<0.05)$. High CD40 expression was associated with TNM stage and lymph node metastasis (both $\mathrm{P}<0.05$ ). Patients with pancreatic cancer have higher serum sCD40L levels $(3.53 \pm 0.70 \mathrm{ng} / \mathrm{ml})$ compared to healthy subjects $(1.81 \pm 0.48 \mathrm{ng} / \mathrm{ml}, \mathrm{P}<0.05)$. rshCD40L significantly inhibited the proliferation of the pancreatic cancer cell lines and induced apoptosis in these cell lines. The co-signaling molecule CD40 is highly expressed in pancreatic cancer tissues and cell lines and rshCD40L is a potential tool for antitumor therapies.
\end{abstract}

Correspondence to: Dr Dechun Li or Dr Xingguo Zhu, Department of General Surgery, The First Affiliated Hospital of Soochow University, Suzhou 215006, P.R. China

E-mail: hesongbing1@126.com

E-mail: zxg45@hotmail.com

*Contributed equally

Key words: pancreatic cancer, CD40, CD40 ligand, proliferation, apoptosis

\section{Introduction}

Pancreatic cancer is one of the most malignant cancer types with a 5-year survival of $<5 \%$. It is notorious for having the poorest prognosis among all the cancer types $(1,2)$. Most of the time, there is no good measures to detect the early pancreatic cancers until it is in the advanced stage when symptoms are developed. Molecular analysis has indicated that specific pathway pattern was involved in the development of pancreatic cancers (3). Efforts have been made to explore new strategies to treat pancreatic cancer, such as immune-biotherapy, which was developed based on the modern oncological molecular biology and immunology, and it shows promise for the future practice of cancer treatment $(4,5)$.

A series of molecules have been identified to be important players in carcinogenesis, among which CD40 is a co-signaling molecule and is a member of tumor necrosis factor receptor (TNF-R) superfamily. CD40 and its ligand, CD40L, play important roles in mediating cellular and humeral immune response by regulating the functions of antigen presenting cells (APC) and T cells. They are gaining increasing attention in the field of tumor immunology (6-8). It has been reported that CD40-CD40L axis was involved in a series of cell biological activities, such as cancer, cardiovascular disease, immune disorders, and even Alzheimer's disease (9-11). CD40 was found to be expressed at an up-regulated level in many epithelial cancers (12-15). Expression of CD40 and CD40L in gastric cancer tissue was positively correlated with lymphatic metastasis and tumor TNM stage (13). In mouse renal cancer cells, CD40 induced cell killing effect by activating Fas (12). CD40 signaling provides critical functions in stimulating antigen presentation, priming of helper and cytotoxic T-cells and a variety of inflammatory reactions.

Studies showed that CD40 was expressed in human pancreatic islets and ductal cells and it was up-regulated in pancreatic cancer (16-18). Because CD40 activation is able to reverse immune suppression and drive antitumor $\mathrm{T}$ cell responses (17), researchers have tried the agonist CD40 antibody to treat pancreatic carcinoma and suggested that CD40 held potential to be a treatment target similarly to that in the treatment of other cancer types (17). Currently, no data exist on the value of CD40-CD40L axis in pancreatic cancer treatment. As an agonist of CD40, CD40L is a good candidate molecule to effectively activate CD40. Here 
we assayed the correlation of CD40-CD40L axis with the clinicopathological characteristics and further evaluated the effects of recombinant soluble human CD40L (rshCD40L) on the biological behavior of pancreatic carcinoma cell lines, to explore a new strategy to treat pancreatic cancer for future cancer biotherapy.

\section{Materials and methods}

Cell culture and tissue samples. The pancreatic cancer cell lines Panc-1, Aspc-1 and Miapaca-2 were purchased from Institute of Cell Biology, Chinese Academy of Sciences, Shanghai. Cells were maintained in RPMI-1640 (Invitrogen, USA) supplemented with $10 \%$ fetal bovine serum (FBS). All cells were cultured at $37^{\circ} \mathrm{C}$ in a humidified atmosphere containing $5 \% \mathrm{CO}_{2}$.

Twenty-six cases of pancreatic cancer tissues were obtained from the patients who received surgery in the Department of General Surgery, the First affiliated Hospital of Soochow University, from June 2008 to June 2010. The patients did not receive any radiotherapy, chemotherapy and immunotherapy. The average age of the patients, 16 males and 10 females, was $59 \pm 1.0$ years (range 38-73 years). The patients were classified according to the AJCC (American Cancer Association, 2007) criteria of TNM grading for pancreatic cancers: 4 cases were in stage I, 11 in stage II, 8 in stage III and 3 in stage IV. Histologically, there were 7 cases of well differentiated adenocarcinomas, 10 cases of moderately differentiated and 9 cases of poorly differentiated adenocarcinomas (Table II). The paratumoral tissues were set as control. The study was approved by the Ethics Committee of the institute and written consent forms were obtained from the patients.

Immunohistochemical detection of CD40 expression in pancreatic cancer. The surgically resected specimens were fixed in $10 \%$ formalin, routinely embedded in paraffin. The slides were immunostained by streptavidin-peroxidase (SP) method. In brief, after slide preparation, the sections were incubated with anti-CD40 mAb [Institute of Biotechnology, Soochow University (5C11)], and followed by SP kit (Beijing Zhong Shan Jin Qiao biotechnique Co., Ltd.) manipulation. The slides were counterstained with hematoxylin and mounted with cover slides for observation. Positive control was set up with specimens known to be positive for CD40. Negative control was set up by replacing anti-CD40 mAb with PBS solution. All the slides were reviewed independently by two experienced pathologists. The brown staining was mainly located on the membrane of the cells. The plasmic staining was also considered as a positive signal. The positivity was expressed by a quantitative evaluation based on 3 parameters $(13,19)$, i.e., intensity (A), percentage of positively stained cells (B) and the multiples from AxB. (A) was graded as: 1, light yellow; 2, yellow; and 3, brown. (B) was defined as the percentage of positive cells in 1000 randomly counted cancer cells under 10 high-power view fields. 0, no positive cells; $1,1-10 \%$ of the cancer cells were positive; $2,11-50 \%$ of the cancer cells were positive; $3,>50 \%$ of the cancer cells were positive. The final score of each specimen was the product of AxB: 0 as negative, 1 as weakly positive (+), 2-3 as positive $(++)$ and $>3$ as strong $(+++)$.
Detection of CD40 expression in pancreatic cancer cell line by RT-PCR. The pancreatic cancer cell lines (Panc-1, Aspc-1 and Miapaca-2) in logarithmic growth phase were lysed with TRIzol (Invitrogen) and total RNA was extracted according to the instructions. RT-PCR was performed according to the manual of the reverse transcriptase kit (Invitrogen). RNA $(0.5 \mu \mathrm{g})$ was reversely transcripted to cDNA for amplification. The primers used for amplification of CD40 and internal control $\beta$-actin were as follows (Shanghai Sangon Biological Engineering Technology Co., Ltd.): CD40, forward: 5'-AGAA GGCTGGCACTGTACGA-3', reverse: 5'-CAGTGTTGGAGC CAGGAAGA-3'; $\beta$-actin: forward: 5'-CAACTCCATCATGAA GTGTAA-3', reverse: 5'-CCACACGGAGTACTTGCGCTG-3'. The expected PCR products for CD40 and $\beta$-actin were 425 and $212 \mathrm{bp}$, respectively. The cycling parameters were: denature at $95^{\circ} \mathrm{C}$ for $3 \mathrm{~min}, 94^{\circ} \mathrm{C}$ for $30 \mathrm{sec}, 60^{\circ} \mathrm{C}$ for $30 \mathrm{sec}, 72^{\circ} \mathrm{C}$ for $1 \mathrm{~min}$, for 30 cycles and additional extension for $7 \mathrm{~min}$ at $72^{\circ} \mathrm{C}$. After PCR amplification, $10 \mu \mathrm{l}$ of the product was resolved electrophoretically on $1.5 \%$ agarose and visualized under gel imaging system (Bio-Rad 3000, USA).

Detection of CD40 expression in pancreatic cancer cell lines by flow cytometry assay. The pancreatic cancer cell lines in logarithmic growth phase were seeded into fetal calf serumcompleted RPMI-1640 media at the concentration of $2 \times 10^{5}$ cells/ $\mathrm{ml}$. The cells were cultured at $37^{\circ} \mathrm{C}$ with $5 \% \mathrm{CO}_{2}$. Twenty-four hours later, the cells were incubated with anti-CD40 mAb for 30 min and analyzed with flow cytometry (Cytomics FC500, Beckman Coulter, USA) for CD40 positivity.

Detection of CD4O in the serum of the patients with ELISA assay. The CD40 level was measured by enzyme-linked immunosorbent assay (ELISA) kit (Bender Medsystems, Austria) according to the manufacturer's instructions. The level of CD40 is presented as $\mathrm{ng} / \mathrm{ml}$.

Determining the cell growth by MTT assay. The pancreatic cancer cell lines were seeded into a 96-well plate at $1 \times 10^{4}$ cells $/ \mathrm{ml}$ and cultured in $5 \% \mathrm{CO}_{2}$ incubator at $37^{\circ} \mathrm{C}$. The cells were randomly divided into 3 groups and incubated with rshCD40L (Pepro Tech Co., USA) (100 ng/ml), rshCD40L $(100 \mathrm{ng} / \mathrm{ml})+$ anti-CD40mAb $(20 \mu \mathrm{g} / \mathrm{ml})$ or PBS as control, respectively. For each treatment 4 replications in parallel were set up with $200 \mu \mathrm{l}$ medium volume and cultured for $72 \mathrm{~h}$. Four hours before the endpoint, $20 \mu 1 \mathrm{MTT}(0.5 \mathrm{mg} /$ ml) (Sigma, USA) was added into the culture media. Then the cells were incubated for another $4 \mathrm{~h}$ and the supernatant was discarded. The precipitation was dissolved with $150 \mu 1$ DMSO/well. The plates were read by plate reader F500 (BioRad, USA) at $492 \mathrm{~nm}$ wavelength for absorbance (A value). The inhibitory rate (IR) of cell growth was calculated with the equation: $I R=(1-\mathrm{A}$ value of test wells/A value of negative control wells) x $100 \%$.

Detection of apoptosis. The pancreatic cancer cell lines were treated with $\mathrm{rshCD} 40 \mathrm{~L}(100 \mathrm{ng} / \mathrm{ml})$ for $72 \mathrm{~h}$. The percentage of apoptotic cells were measured with TUNEL assay (5). PBS was set up as control treatment. The effects of rshCD40L at various concentrations on apoptosis of the pancreatic cancer cell lines were measured with Annexin V/PI staining method. 


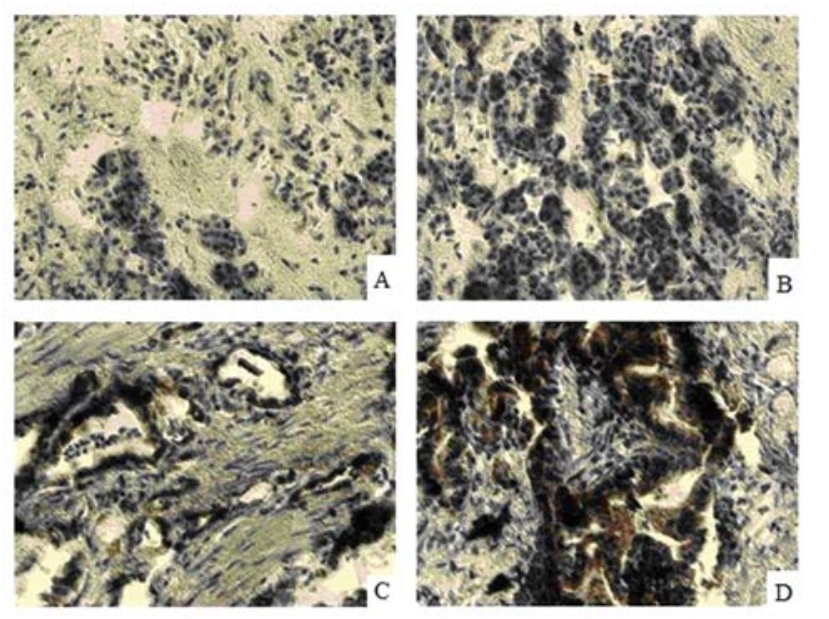

Figure 1. Expression of CD40 in pancreatic cancer tissues and paratumoral tissues (x40). CD40 was expressed at a higher level in pancreatic cancer tissues than in normal tissues. (A and B) No expression of CD40 in paratumoral tissues; $(C$ and $D)$ Typical positive expression of CD40 in pancreatic tissues.

In brief, cells in logarithmic growth phase were seeded into a 6-well plate. When the cells grew to $75 \%$ confluence, they were treated with media containing $1.0,2.0$ and $3.0 \mu \mathrm{g} / \mathrm{ml}$ rshCD40L, respectively. After a period of incubation, the cells were collected and incubated with $5 \mu \mathrm{l}$ Annexin V and PI (both with the final concentration of $1 \mu \mathrm{g} / \mathrm{ml}$ ) for $15 \mathrm{~min}$ in the dark. Then the cell samples were assayed with flow cytometry.

Statistical analyses. The data are presented as mean \pm SD and analyzed with SPSS13.0 software. The differences between two groups were compared with Mann-Whitney U test. The correlation between CD40 expression and the clinicopathological parameters was tested with Fisher's exact test. $\mathrm{P}<0.05$ was considered as significant.

\section{Results}

The correlation of CD40 expression in pancreatic cancer specimens with the clinicopathological parameters of the patients. Immunohistochemical staining showed that CD40 was expressed in pancreatic cancer tissues at different levels. The staining signal was located on the membrane and, partially, in the cytoplasm. In the 26 cases of pancreatic cancer patients, 18 cases (69.2\%) were positive for CD40 expression, among whom 10 $(38.5 \%)$ were at strong level of CD40 expression. In the paratumoral pancreatic cancer tissues, CD40 was absent or weakly expressed. The difference was significant $(\mathrm{P}<0.01)$ (Fig. 1 and Table I). We further analyzed the correlation of CD40 expression with the clinicopathological parameters and found that CD40 was positive in $46.7 \%$ (7/15) of the patients at stages I and II of their diseases, but in $90.9 \%$ (10/11) of those at stages III and IV. In the patients with lymphatic metastasis, $86.7 \%(13 / 15)$ were positive for CD40, comparing to that of $45.5 \%$ (5/11) in those without lymphatic metastasis $(\mathrm{P}<0.05)$. No significant difference was found in other parameters, such as age, gender, tumor size, location and histological grade $(\mathrm{P}>0.05)$ (Table II).

The concentration of CD4OL in the peripheral blood. We detected the levels of $\mathrm{SCD} 40 \mathrm{~L}$ in of peripheral blood of
Table I. Immunohistochemical staining of CD40 in the pancreatic cancer tissues.

\begin{tabular}{lcc}
\hline $\begin{array}{l}\text { CD40 } \\
\text { expression }\end{array}$ & $\begin{array}{c}\text { Pancreatic } \\
\text { cancer (n) }\end{array}$ & $\begin{array}{c}\text { Paratumoral } \\
\text { tissue (n) }\end{array}$ \\
\hline- & 8 & 19 \\
+ & 5 & 7 \\
++ & 3 & 0 \\
+++ & 10 & 0 \\
Total & 26 & 26 \\
P-value & & P $<0.01$ \\
\hline
\end{tabular}

-, negative; +, weakly positive; ++, positive; and +++, strongly positive.

Table II. The correlation of CD40 expression with clinicopathological characteristics.

\begin{tabular}{lrrr}
\hline $\begin{array}{l}\text { Clinicopathological } \\
\text { characteristics }\end{array}$ & $\begin{array}{c}\text { No. of } \\
\text { cases (n) }\end{array}$ & $\begin{array}{c}\text { CD40 } \\
(\%)\end{array}$ & P-value \\
\hline $\begin{array}{l}\text { Age (years) } \\
\leq 60\end{array}$ & 12 & $8(75.0)$ & 0.793 \\
$>60$ & 14 & $10(71.4)$ &
\end{tabular}

Gender

$\begin{array}{lrrr}\text { Male } & 16 & 12(75.0) & 0.664 \\ \text { Female } & 10 & 6(60.0) & \end{array}$

Tumor size (cm)

$\begin{array}{rrrr}\leq 5 & 15 & 11(73.3) & 0.683 \\ >5 & 11 & 7(63.6) & \end{array}$

Tumor location

$\begin{array}{lrrr}\text { Head section } & 19 & 13(68.4) & 0.882 \\ \text { Body and tail } & 7 & 5(71.4) & \end{array}$

Histology

$\begin{array}{llll}\text { Well differentiated } & 7 & 3(42.9) & 0.361\end{array}$

Morderately differentiated $\quad 10 \quad 5(50.0)$

$\begin{array}{lll}\text { Poorly differentiated } & 9 & 7(77.8)\end{array}$

TNM stage

$\begin{array}{lrrr}\text { Stages I and II } & 15 & 7(46.7) & <\mathbf{0 . 0 5} \\ \text { Stages III and IV } & 11 & 10(90.9) & \end{array}$

Lymphatic metastasis

$\begin{array}{llll}\text { Yes } & 15 & 13(86.7) & <\mathbf{0 . 0 5}\end{array}$

No $11 \quad 5(45.5)$

10 pancreatic cancer patients and 10 healthy volunteers and found that the pancreatic cancer patients had a much higher 


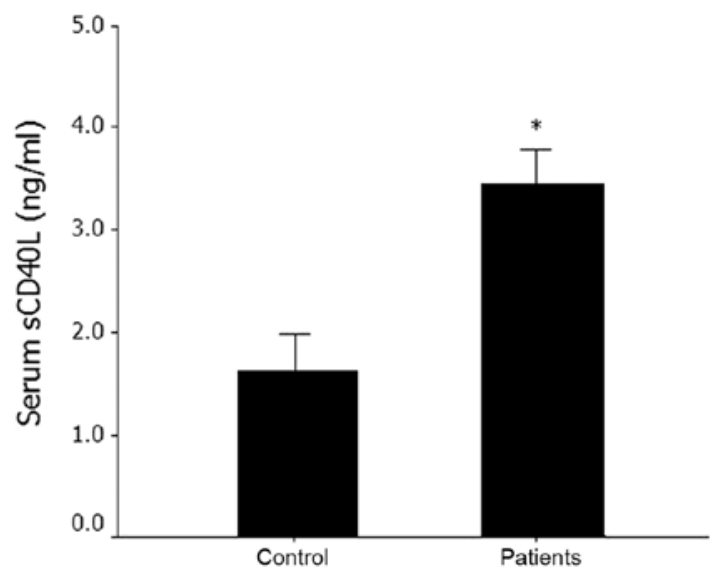

Figure 2. ELISA assay for CD40 level in the peripheral blood of the pancreatic cancer patients. In the pancreatic cancer patients, the soluble CD40 was significantly higher than that of the control patients ( $\mathrm{P}<0.05$ compared with control).

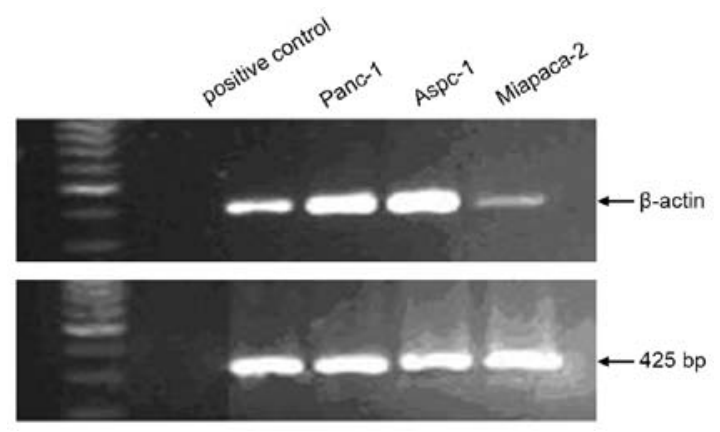

Figure 3. The expression of CD40 at mRNA level. The pancreatic cancer cells expressed CD40 mRNA at various levels. Lane 1, positive control; lanes 2-4, Panc-1, Aspc-1 and Miapaca-2, respectively. level of sCD $40 \mathrm{~L}(3.53 \pm 0.70 \mathrm{ng} / \mathrm{ml})$ in the peripheral blood than the control subjects $(1.81 \pm 0.48 \mathrm{ng} / \mathrm{ml})(\mathrm{P}<0.05)$ (Fig. 2).

Expression of CD40 in the pancreatic cancer cell lines. To further confirm the expression of CD40 in pancreatic cancer, we detected the expression of CD40 in a panel of pancreatic cancer cell lines, including Panc-1, Aspc-1 and Miapaca-2. RT-PCR was employed to detect the mRNA level of CD40 in these cell lines. Results showed that the three cell lines expressed CD40 at certain levels (Fig. 3). Flow cytometry assay of CD40 expression in these cell lines showed that the percentage of cells with positive CD40 expression was $43.5,32.8$ and $21.9 \%$, respectively (Fig. 4).

The growth inhibition of pancreatic cancer cell lines by recombinant soluble human CD40 ligand ( $r s h C D 40 L)$. We performed experiments to evaluate the growth suppression of pancreatic cancer cell lines by rshCD40L. It was indicated that rshCD40L was highly active in suppressing the growth of Panc-1,Aspc-1 and Miapaca- 2 cells, with the inhibitory rates of $34.7 \pm 1.2,25.3 \pm 1.0$ and $15.8 \pm 2.1 \%$, respectively. Compared with PBS control group, rshCD40 significantly suppressed pancreatic cancer cell growth $(\mathrm{P}<0.05)$, while this effect was largely rescued by the addition of anti-CD40mAb (Fig. 5).

Induction of apoptosis by rshCD40L in pancreatic cancer cells. To show whether rshCD40L was active in mediating cancer cell apoptosis, we then assayed, by the TUNEL and cytometry analysis, the apoptosis-inducing ability of rshCD40L. Results showed that there were $17.2 \pm 0.7,13.2 \pm 0.4$ and $10.5 \pm 0.6 \%$ of Panc-1, Aspc-1 and Miapaca-2 cells, respectively, that underwent apoptosis in the presence of $100 \mathrm{ng} / \mathrm{ml}$ of $\mathrm{rshCD} 40 \mathrm{~L}$, which

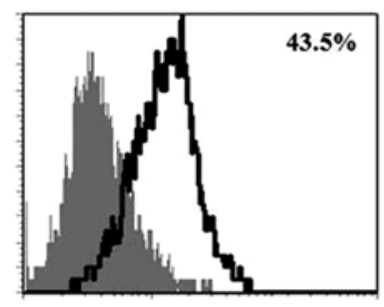

Panc-1

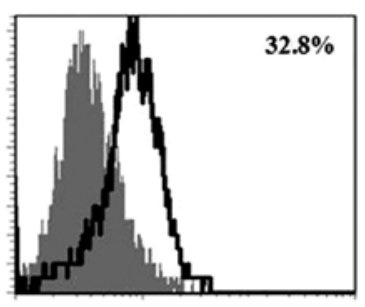

Aspc-1

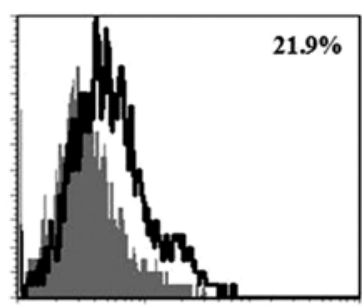

Miapaca-2

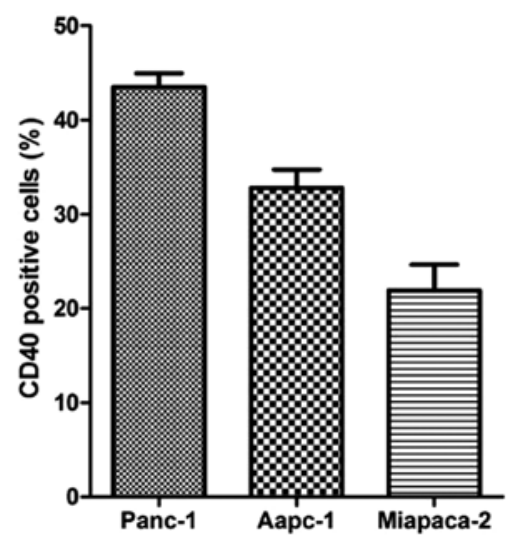

Figure 4. Expression of CD40 in the pancreatic cancer cells by flow cytometry assay CD40 was expressed in 43.5, 32.8 and 21.9\% of the Panc-1, Aspc-1 and Miapaca-2 cells, respectively. 

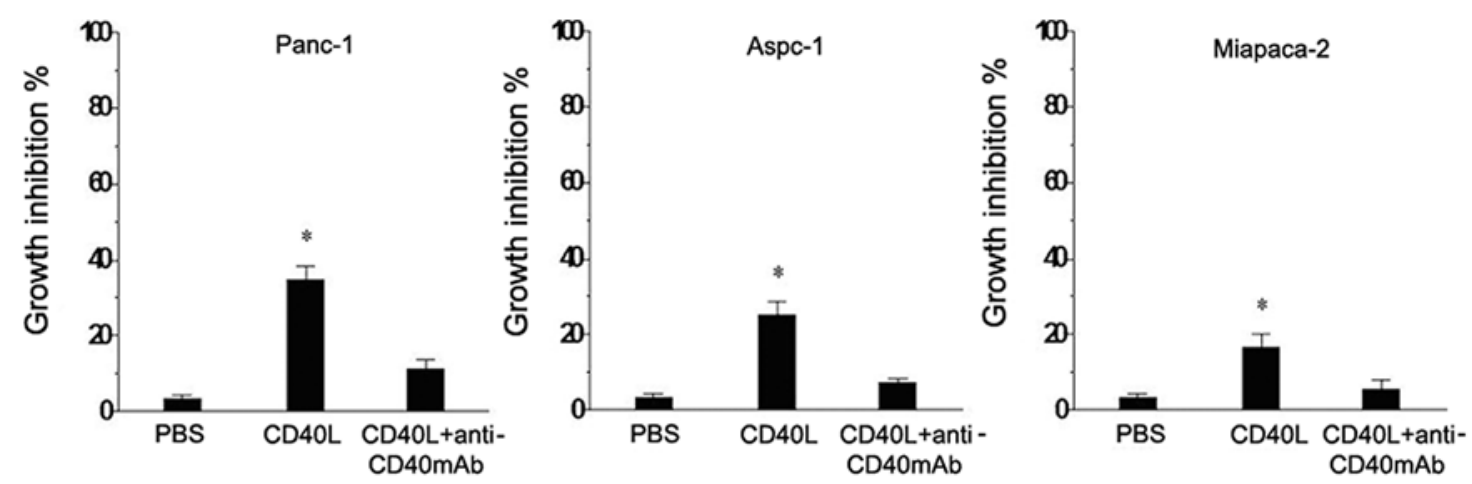

Figure 5. Suppression of rshCD40L on cancer cell growth. CD40L significantly suppressed the growth of these three pancreatic cancer cells and the expression was largely rescued by the addition of anti-CD40mAb (" $\mathrm{P}<0.05$, compared with control and rshCD40L + anti-CD $40 \mathrm{mAb}$ group).

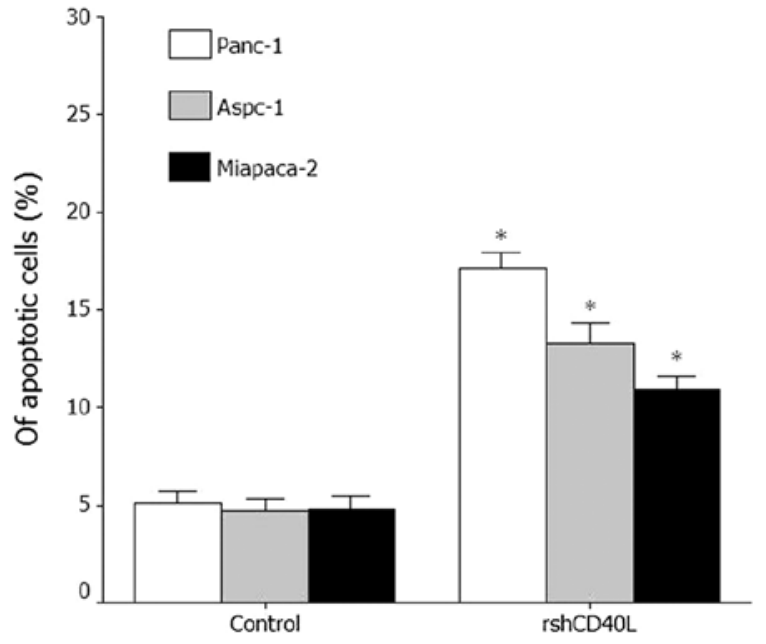

Figure 6. rshCD40L induced apoptosis of cancer cells. After addition of rshCD40L $(100 \mathrm{ng} / \mathrm{ml})$ into the medium, the pancreatic cancer cells encountered massive apoptosis, and the Panc-1 cell the most sensitive to rshCD40 treatment ( $\mathrm{P}<0.05$, compared with the respective control group).

were all significantly higher than that of control group $(\mathrm{P}<0.05)$ (Fig. 6). Interestingly, we found that CD40L was more potent in inhibiting the growth and induce apoptosis in the pancreatic cancer cells with higher CD40 level, like Panc-1, than that with lower CD40 level. Subsequently, we further evaluated the dosage-dependent apoptosis intensity of rshCD40L in Panc-1 cells. With the increase of rshCD40L, higher percentage of the cells underwent apoptosis. At 1.0, 2.0 or $3.0 \mu \mathrm{g} / \mathrm{ml}$ of rshCD $40 \mathrm{~L}$, there were $10.09,11.74$ and $15.59 \%$ of the cells that underwent apoptosis, respectively, all were significantly higher than that of $6.78 \%$ in the control group $(\mathrm{P}<0.05)$ (Fig. 7).

\section{Discussion}

In this study, we reported that CD40-CD40L interaction may play an important role in the development, and hence the future treatment, of pancreatic cancer. We found CD40 was overexpressed in pancreatic cancer tissues, compared with the normal pancreatic tissue. The expression of CD40 in the pancreatic cancer cell lines was consistent with the trend in cancer tissues. CD40L treatment was able to induce growth inhibition and
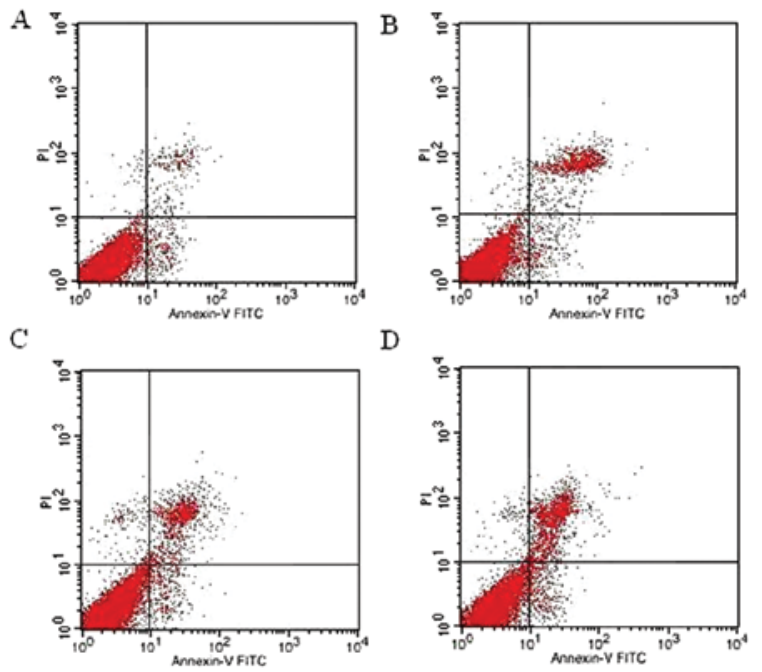

$\mathrm{D}$
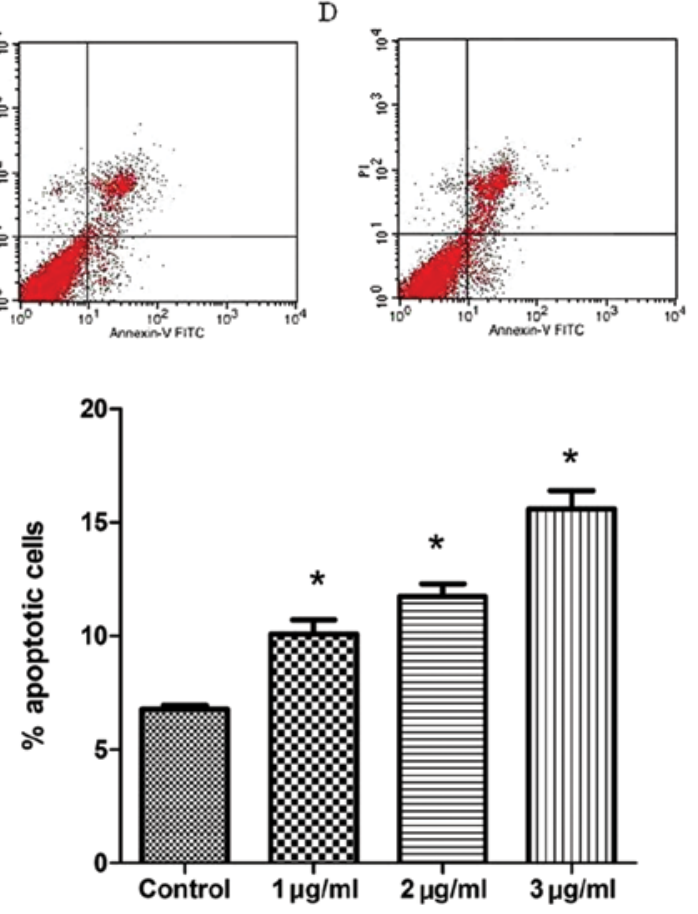

Figure 7. The dose-dependent apoptosis of Panc-1 cells under rshCD40L treatment. rshCD40L induced apoptosis in Panc-1 cells at the concentration of $1.0 \mu \mathrm{g} / \mathrm{ml}$, and achieved increasing proportion of apoptotic cells at higher rshCD40 concentrations by flow cytometry assay. (A) control; (B) $1.0 \mu \mathrm{g} / \mathrm{ml}$; (C) $2.0 \mu \mathrm{g} / \mathrm{ml} ;$ (D) $3.0 \mu \mathrm{g} / \mathrm{ml}$.

apoptosis in pancreatic cancer cells, especially in the cancer cell lines with higher CD40 expression. These data provide new clues to pancreatic cancer immunity and treatment.

Primarily, CD40 is expressed in monocytes, tissue macrophages, B lymphocytes, and dendritic cells (DC). Recent studies have also found abnormal expression of CD40 in a series of 
epithelial tumors such as ovary cancer, prostate cancer, breast cancer, lung cancer and melanoma (20). It was reported that CD40 expression was correlated with acute lymphoblastic leukemias (ALLs) and B-lineage non-Hodgkin's lymphomas (NHLs) (21). CD40 expression has been shown to be associated with cancer metastasis. High level of CD40 in gastric cancer was associated with cancer invasion and liver metastasis (22). Also, lack of CD40 receptor-ligand system reduced the risk of lung metastasis in a model system (23). These reports support our findings of the association of CD40 expression and cancer development and metastasis in pancreatic cancer.

In the present study, we investigated the expression of CD40 in pancreatic cancer tissues and found that CD40 was expressed mainly on the membrane of the cancer cells at various levels. A small part of CD40 was located in the cytoplasm, 69.2\% of the specimens were positive for CD40 expression of which $38.5 \%$ were intensely expressed for CD40. RT-PCR and flow cytometry assay showed various expression of CD40 in pancreatic cancer cells. It was reported that CD40 contributed to tumor cell survival and resistance to chemotherapy in follicular lymphoma, chronic B lymphocytic leukemia and Hodgkin's disease (20). Also, CD40 was found to be highly expressed in the tumor blood vessels of kidney and breast cancers, suggesting a role of CD40 in the angiogenesis of cancers (24). Sabel et al reported the expression of CD40 in lung cancer tissues was associated with the distal metastasis and poor prognosis of lung cancer (25). In the study, $78 \%$ of the cell lines from the patient were found to be CD40-positive and all of these patients were encountered with local or distal metastasis, while cell lines negative for CD40 were all from tumors in stage I, and these patients showed no signs of local or distal metastasis. In the present study, we found that CD40 was higher in stage III and IV than stage I and II cancers. Moreover, CD40 expression was found to be closely associated with the development and metastasis of pancreatic cancer cells, suggesting that CD40 may be involved in the invasion and metastasis of pancreatic cancer. However, the mechanism on how CD40 was involved in the process remained to be further investigated. Recent data showed that down-regulation of CD40 on DC cell surface and low-level CD40L on $\mathrm{T}$ cell surface of patients with pancreatic cancer impaired the function of DC cells, which was closely associated with the immunosuppressive status of cancer patients $(26,27)$. Therefore, CD40 may be a valuable marker to predict the malignancy, invasive and metastatic potential and prognosis in pancreatic cancer patients.

CD40 and CD40L modulate the anti-tumor immunity by influencing the development, activation, proliferation and differentiation of a series of immune cells (27). Unfortunately, the mechanism by which CD40-CD40L regulates immune functions is not fully known. There are reports indicating that CD40-CD40L suppressed cancer cell growth by promoting cell cycle arrest and/or apoptosis $(28,29)$. In addition, studies have shown that expression of CD40 or its ligand on the surface of cancer cells increased the level of cellular adhesion molecule 1 (ICAM-1), unregulated Fas expression and sensitized the cancer cells to Fas-mediated apoptosis (30). Among its direct effects on the tumor, tumor necrosis factor receptor-associated factor (TRAF) was considered as the key intermediate molecule delivering CD40 signals to play physiological functions (31). CD40-regulated genes include TNF (LT and CD70) and
TNF-R family members (TNF-R1, TNF-R2 and CD40), cyclins (Cdk4 and Cdk6), anti-apoptotic members (CIAP and Bcl-X ${ }_{\mathrm{L}}$ ) and apoptotic component DR3, while the upstream regulators directly mediate the transcription of CD40 (31). Gallagher et al reported that CD40 was highly expressed in epithelia-derived ovary cancer cells and CD40L was able to significantly inhibit the growth of CD40+ ovary cancer cells and promote apoptosis of the cancer cells (32). Consistent with this, our data showed that rshCD40L inhibited the growth of $\mathrm{CD} 40^{+}$pancreatic cancer cells (Pan-1, Aspc-1 and Miapaca-2) and induced apoptosis. Other studies also indicated that the role of CD40-CD40L in cancer immunity may involve activating DC to enhance the antigen-presenting, upregulating the expression of co-signaling molecules, and promoting the secretion of cytokines $(29,33)$. However, the exact mechanisms of CD40-CD40L in pancreatic cancer remained to be clarified. Interestingly, we found here that CD40 exerted stronger growth inhibition and apoptosis-inducing effects on the pancreatic cells with higher CD40 expression. This fact suggests up-regulation of CD40 level may facilitate the efficacy of CD40L in cancer cells. Therefore, a novel strategy based on the CD40-CD40L network may be helpful in the targeted therapy of cancer.

We found that the $\mathrm{sCD} 40 \mathrm{~L}$ in the serum of patients $(3.53 \pm 0.70 \mathrm{ng} / \mathrm{ml})$ with pancreatic cancers was higher than that in control subjects $(1.81 \pm 0.48 \mathrm{ng} / \mathrm{ml})$. Our previous study demonstrated that higher SCD40L was also detected in patients with gastric cancers than in healthy controls (13). Moreover, higher sCD40L was correlated with tumor metastasis and progression (13). Though there is little explanation for this higher level of sCD40L in cancer patients compared to those in healthy controls, it would be of interest to evaluate the predicting value of SCD40L for cancer development.

Taken together, we found in this study that the co-signaling molecule CD40 was expressed at a higher level in pancreatic cancer tissues and cell lines. Recombinant CD40L was powerful in suppressing pancreatic cancer cell growth and inducing apoptosis, showing a potent biological activity in vitro. We also found that CD40 expression was closely correlated with TNM stages and lymphatic metastasis. Though we are not aware of the exact mechanism, the broad signaling network of CD40-CD40L may be involved in the metastasis-associated pathways. Thus, CD40-CD40L pathway may be a good target to enhance the tumor immunosurveillance and anti-tumor immune response. This study provides information useful for new strategies in the development of targeted therapy against pancreatic cancer.

\section{Acknowledgements}

This study was supported by grants from Medical Science and Technology Development Foundation, Jiangsu Province Department of Health (no. H201013), Program for Postgraduate Research Innovation in University of Jiangsu Province (no. CX10B_054Z), and Project of Youth Foundation in Science and Education of Department of Public Health of Suzhou (no. SWKQ1004).

\section{References}

1. Hidalgo M: Pancreatic cancer. N Engl J Med 362: 1605-1617, 2010 . 
2. Jemal A, Siegel R, Xu J and Ward E: Cancer statistics, 2010. CA Cancer J Clin 60: 277-300, 2010.

3. Greer JB and Brand RE: New developments in pancreatic cancer. Curr Gastroenterol Rep 13: 131-139, 2011

4. Kalyn R: Overview of targeted therapies in oncology. J Oncol Pharm Pract 13: 199-205, 2007.

5. He S, Wang L, Wu Y, Li D and Zhang Y: CCL3 and CCL20recruited dendritic cells modified by melanoma antigen gene-1 induce anti-tumor immunity against gastric cancer ex vivo and in vivo. J Exp Clin Cancer Res 29: 37, 2010.

6. Loskog AS and Eliopoulos AG: The Janus faces of CD40 in cancer. Semin Immunol 21: 301-307, 2009.

7. Chakrabarti S, Rizvi M, Pathak D, Kirber MT and Freedman JE: Hypoxia influences CD40-CD40L mediated inflammation in endothelial and monocytic cells. Immunol Lett 122: 170-184, 2009.

8. Vonderheide RH: Prospect of targeting the CD40 pathway for cancer therapy. Clin Cancer Res 13: 1083-1088, 2007.

9. Chatzigeorgiou A, Lyberi M, Chatzilymperis G, Nezos A and Kamper E: CD40/CD40L signaling and its implication in health and disease. Biofactors 35: 474-483, 2009.

10. Giunta B, Rezai-Zadeh K and Tan J: Impact of the CD40-CD40L dyad in Alzheimer's disease. CNS Neurol Disord Drug Targets 9: 149-155, 2010

11. Pamukcu B, Lip GY, Snezhitskiy V and Shantsila E: The CD40CD40L system in cardiovascular disease. Ann Med 43: 331-340, 2011.

12. Lee JK, Seki N, Sayers TJ, et al: Constitutive expression of functional CD40 on mouse renal cancer cells: induction of Fas and Fas-mediated killing by CD40L. Cell Immunol 235: 145-152, 2005.

13. Li R, Chen WC, Pang XQ, Hua C, Li L and Zhang XG: Expression of CD40 and CD40L in gastric cancer tissue and its clinical significance. Int J Mol Sci 10: 3900-3917, 2009.

14. Eck SC and Turka LA: Generation of protective immunity against an immunogenic carcinoma requires CD40/CD40L and B7/CD28 interactions but not CD4(+) T cells. Cancer Immunol Immunother 48: 336-341, 1999

15. Voorzanger-Rousselot $\mathrm{N}$ and Blay JY: Coexpression of CD40 and CD40L on B lymphoma and carcinoma cells: an autocrine anti-apoptotic role. Leuk Lymphoma 45: 1239-1245, 2004.

16. Klein D, Timoneri F, Ichii H, Ricordi C and Pastori RL: CD40 activation in human pancreatic islets and ductal cells. Diabetologia 51: 1853-1861, 2008

17. Beatty GL, Chiorean EG, Fishman MP, et al: CD40 agonists alter tumor stroma and show efficacy against pancreatic carcinoma in mice and humans. Science 331: 1612-1616, 2011.

18. Nanda S: Cancer: CD40 agonists - a promising new treatment for pancreatic cancer? Nat Rev Gastroenterol Hepatol 8: 300, 2011.

19. Wu Y, Wang L, He X, et al: Expression of CD40 and growthinhibitory activity of CD40 ligand in colon cancer ex vivo. Cell Immunol 253: 102-109, 2008.
20. Tong AW and Stone MJ: Prospects for CD40-directed experimental therapy of human cancer. Cancer Gene Ther 10: 1-13, 2003.

21. Uckun FM, Gajl-Peczalska K, Myers DE, Jaszcz W, Haissig S and Ledbetter JA: Temporal association of CD40 antigen expression with discrete stages of human B-cell ontogeny and the efficacy of anti-CD40 immunotoxins against clonogenic B-lineage acute lymphoblastic leukemia as well as B-lineage non-Hodgkin's lymphoma cells. Blood 76: 2449-2456, 1990.

22. Lo SS, Wu CW, Chi CW, Li AF, Chen JH and Lui WY: High CD40 expression in gastric cancer associated with expanding type histology and liver metastasis. Hepatogastroenterology 52: 1902-1904, 2005.

23. Ingersoll SB, Langer F, Walker JM, et al: Deficiencies in the CD40 and CD154 receptor-ligand system reduce experimental lung metastasis. Clin Exp Metastasis 26: 829-837, 2009.

24. Tai YT, Podar K, Gupta D, et al: CD40 activation induces p53-dependent vascular endothelial growth factor secretion in human multiple myeloma cells. Blood 99: 1419-1427, 2002.

25. Sabel MS, Yamada M, Kawaguchi Y, Chen FA, Takita H and Bankert RB: CD40 expression on human lung cancer correlates with metastatic spread. Cancer Immunol Immunother 49: 101-108, 2000.

26. Shurin MR, Yurkovetsky ZR, Tourkova IL, Balkir L and Shurin GV: Inhibition of CD40 expression and CD40-mediated dendritic cell function by tumor-derived IL-10. Int J Cancer 101: 61-68, 2002.

27. Yanagimoto H, Takai S, Satoi S, et al: Impaired function of circulating dendritic cells in patients with pancreatic cancer. Clin Immunol 114: 52-60, 2005.

28. Quezada SA, Jarvinen LZ, Lind EF and Noelle RJ: CD40/CD154 interactions at the interface of tolerance and immunity. Annu Rev Immunol 22: 307-328, 2004.

29. Scott K, Manunta M, Germain C, et al: Qualitatively distinct patterns of cytokines are released by human dendritic cells in response to different pathogens. Immunology 116: 245-254, 2005.

30. Schwulst SJ, Grayson MH, DiPasco PJ, et al: Agonistic monoclonal antibody against CD40 receptor decreases lymphocyte apoptosis and improves survival in sepsis. J Immunol 177: 557-565, 2006

31. Zirlik A, Bavendiek U, Libby P, et al: TRAF-1, -2, -3, -5, and -6 are induced in atherosclerotic plaques and differentially mediate proinflammatory functions of CD40L in endothelial cells. Arterioscler Thromb Vasc Biol 27: 1101-1107, 2007.

32. Gallagher NJ, Eliopoulos AG, Agathangelo A, Oates J, Crocker J and Young LS: CD40 activation in epithelial ovarian carcinoma cells modulates growth, apoptosis, and cytokine secretion. Mol Pathol 55: 110-120, 2002.

33. Schnurr M, Chen Q, Shin A, et al: Tumor antigen processing and presentation depend critically on dendritic cell type and the mode of antigen delivery. Blood 105: 2465-2472, 2005. 